\title{
EDITORIAL: PERSPECTIVAS INTERNACIONAIS CRÍTICAS SOBRE O MUNDO DAS ORGANIZAÇÕES
}

\section{Ana Sílvia Rocha Ipiranga ${ }^{1}$ Bill Cooke ${ }^{2}$}

Esta edição especial teve como objetivo reunir trabalhos que explorassem o mundo das organizações, envolvendo, em um contexto internacional, autores intelectualmente engajados e pouco ortodoxos e que contribuíssem para a prática de pesquisas críticas no campo da Administração.

Os artigos convidados a comporem este número especial foram traduzidos para a língua portuguesa e em muitas de suas partes, revisados e alterados, em relação às suas apresentações originais. Contudo, não houve pela nossa parte, enquanto editores desse número especial, pelo menos a princípio, a ideia de sugerir um tema articulador e aglutinador em torno do qual os autores convidados a participar problematizariam diferentes questões atinentes ao mundo das organizações. Os diversos e diferentes temas articulados entre o conjunto de artigos escolhidos para a composição desse número delineariam, sobretudo, um especifico fio condutor de discussão, qual seja, aquele da crítica, realçando o caráter multifacetado do estudo da vida organizacional.

Contudo, além da crítica e contradizendo esta primeira posição editorial, o leitor observará que um fio condutor delineia e conduz a leitura a similares campos e temas de estudos entre os cinco trabalhos que compõem este número especial, qual seja: a questão de práticas alternativas à uma gestão instrumental de base neoliberal em tempos de crises financeiras, terremotos e desastres ambientais e de mudanças organizacionais radicais.

Observamos uma mútua e até mesmo uma dialética relação entre essa busca por práticas não-gerenciais ou anti-gerenciais alternativas e os objetos de análise e campos de pesquisa escolhidos pelos autores que

\footnotetext{
${ }^{1}$ Universidade Estadual do Ceará (UECE), E-mail: anasilviaipi@uol.com.br

${ }^{2}$ University of York (UK), E-mail: bill.cooke@ york.ac.uk

Revista Brasileira de Estudos Organizacionais • v. 2. n. 1, p. 1-5, jun. 2015, eISSN: 2447-4851

Sociedade Brasileira de Estudos Organizacionais
} 


\section{EDITORIAL: PERSPECTIVAS INTERNACIONAIS CRÍTICAS SOBRE O MUNDO DAS ORGANIZAÇÕES \\ Ana Sílvia Rocha Ipiranga / Bill Cooke}

contribuiram para este número especial. Os campos de interesse não são, de modo geral, os campos de estudos das variadas corporações modernas que os Estudos Organizacionais norte-americanos, arquetipicamente, escolhem para garantir o exame da forma "natural" de organização. Os eventos e práticas descritos não são "tipicos" dessa versão norteamericana corporativista. No entanto, eles são típicos do mundo em que vivemos e, particularmente, das prioridades imediatas e problemas que as sociedades enfrentam e tentam resolver através de uma ação organizada.

Há então, um contraste entre a estreiteza do mainstream norteamericano, ou mesmo do Atlântico Norte, e as teorias e práticas organizacionais frente a magnitude das "crises" ou da "pobreza". Esse contraste põe em nítido relevo a extensão na qual este mainstream limita as condições de possibilidades.

Assim, quando as organizações tentam, e falham, ao se engajarem com os fenômenos que tenham importancia e implicações sociais, com 'aderência' social para além do mundo da organização e da teoria organizacional, sejam nas noções de democracia (aqui, por exemplo, discutidas por Linstead e Cooke), crise ambiental (Clegg et al., e Srinivas) ou até mesmo a morte (Bell e Taylor), o mainstream dos Estudos Organizacionais do Atlântico Norte e as suas reivindicações tácitas para o universalismo estão, portanto, revelados como problemáticos.

Não obstante, a maioria das contribuições reunidas neste número especial são originárias dos Estudos Organizacionais de instituições do Atlântico Norte. Como é o caso em todo o mundo, essas instituições colocam fortes pressões sobre os estudiosos individuais para restringir este tipo de publicação em periódicos reconhecidos, neste caso, as revistas de língua Inglesa editadas no Reino Unido e nos EUA. A decisão dos autores de publicar trabalhos em Português, portanto, reflete algum compromisso de envolvimento, das suas partes, com os colegas brasileiros. Da mesma forma, a SBEO, na edição desse número especial exemplificou uma das variadas possibilidades de aprendizagem para as partes aqui envolvidas. Que os estudiosos de todo o mundo possam se unir nesta recíproca, e isso tem que ser dito, forma inovadora e distintiva, é talvez uma lição a partir da qual outros possam aprender.

Enfim, estas recíprocas ações talvez sejam um indicativo de uma crescente solidariedade internacional em torno do potencial de uma nova 
versão dos estudos e teorias da organização, com um distanciamento descentrado do Atlântico Norte. Então, em alguns sentidos, a presença dos nossos colaboradores internacionais neste número especial representa um compromisso intelectual e político, para ambos, deles proprios e para a SBEO. Nesta prática editorial, assim como, profundamente enraizado nas práticas e conteúdos incorporados por esta edição especial, reconhecemos talvez, também, a presença de um novo internacionalismo, que não tem a pretensão de negar a existência da dinâmica do saber-poder, mas no entanto, procura por um engajamento acadêmico mútuo.

Iniciamos esta edição com o estudo de Stefhen Linstead intitulado "O Lado Sombrio do Caminho: Estudos Críticos em Administração e Relações Públicas Críticas". O autor contextualiza a discussão nas práticas de comunicação "pacificadoras" que vêm sendo utilizadas pelas Relações Públicas (RP) corporativas em momento de crises financeiras e desastres ambientais. Para isso, Linstead revisa a história das relações públicas (RP) sob a lente conceitual do desejo e do poder, deslocando a atenção na maneira como estes têm sido repensados através do século XX desde Freud, via teoria crítica, Lacan e Deleuze, e, particularmente em relação à questão da ideologia. $\mathrm{O}$ autor conclui ressaltando as possibilidades de diálogo entre a emergente área de Relações Públicas Críticas (RPC) e os Estudos Críticos em Administração (ECA), descrevendo como RPC e ECA podem desenvolver linhas colaborativas de pesquisas.

Em seguida temos a contribuição de Ace Volkmann Simpson, Stewart Clegg, Miguel Pina e Cunha e Ana Regina Marcelino "Expressões de Compaixão: Práticas Organizacionais no Rescaldo de uma Crise". Os autores através de uma pesquisa empírica baseada em casos coligidos junto a organizações afetadas pelas cheias de Brisbane em 2011, colocam em discussão a perspectiva dominante da literatura sobre gestão das crises que aborda a compaixão de um modo instrumental. Ao conceituarem a compaixão como prática social complexa, os autores problematizam esta posição enfatizando a gestão de crises como processo contínuo, no qual as organizações expressam compaixão como prática quotidiana, nas rotinas e políticas do dia-a-dia, sendo esta cultivada e (re) constituída através de modos de saber, relações dinâmicas de poder e processos emergentes.

O terceiro artigo intitulado "A 'Fixação' do Poder: o Que os Desastres Podem nos Dizer sobre Gestão", Nidhi Srinivas reflete sobre os pontos em comum entre dois recentes terremotos ocorridos em 2010, o primeiro em 
janeiro em Porto Príncipe no Haiti; e o segundo, em fevereiro, em Constituición no Chile. Baseado nos referentes conceituais acerca do capitalismo de desastre e do gerencialismo de desastre, o autor enfatiza que esses dois desastres revelaram controvérsias agudas acerca da gestão de resposta a desastres. Nesse contexto, as políticas neoliberais limitaram o alcance e (em alguns casos) a capacidade do Estado em atuar em momentos de desastres, enquanto criam espaços para a intervenção da sociedade civil. Por fim, Srinivas sugere uma tríade conceitual para explicar uma "fixação" do poder, de como as intervenções gerenciais na ajuda humanitária excluem o controle local em detrimento da direção e da qualidade da ajuda.

A presente edição avança com o estudo de Bill Cooke intitulado "Administração e Gestão de Desenvolvimento do Atlântico Norte no Governo do Brasil: uma Análise Histórica do Banco Mundial". O autor faz referência a literatura pertinente de Gestão Internacional (GI) quando esta evidencia que os países com o status de Terceiros, Sulistas, ou em Desenvolvimento são construídos e sustentados pelo ato de exclusão no exercício de um poder geopolítico do conhecimento. Nesse contexto e a partir de uma análise crítica histórica de documentos do Banco Mundial o autor problematiza a auto terminologia universal e deslocalizada das expressões 'Administração do Desenvolvimento' e ou 'Gestão do Desenvolvimento', sugerindo como mais apropriado o termo 'Administração e Gestão do Desenvolvimento do Atlântico Norte' ('North Atlantic Development Administration and Management' - sigla em Inglês NADAM - acrônimo em Inglês - SWIMMING). Por fim o autor afirma que GI e SWIMMING não devem ser vistos como isolados um do outro e questiona quais finalidades servem para ambos sua ignorância mútua aparente?

Encerramos este número especial com o trabalho de Emma Bell e Scott Taylor - "Para Além da Superação e do Recomeço: Novas Perspectivas sobre Morte Organizacional Simbólica, Perda e Luto" - no qual os autores trazem o tema da morte de volta aos Estudos Organizacionais. Os autores investigam as diferenças existentes entre a literatura sobre sociologia da morte e seu processo, que abandonaram extensivamente os modelos de fases de perda e luto, e a literatura sobre morte organizacional, que continua apegada ao modelo de Kübler-Ross de luto como base para analisar como as pessoas respondem à perda induzida por mudança organizacional radical. Os autores argumentam que um dos motivos pelos quais essa situação persiste se explica pelas diferenças culturais e 
pela dominação das perspectivas culturais norte-americanas na articulação da teoria organizacional. Ao final os autores sugerem temas de análises utilizando estudos antropológicos, sociológicos e históricos sobre a morte e o luto em culturas latino-americanas, como base para o desenvolvimento de concepções plurais de perda e luto no contexto de mudança organizacional.

Por fim, nós do Coletivo Editorial da RSBEO gostaríamos de agradecer aos autores que dispuseram seus trabalhos para serem publicados neste número especial e pelas disponibilidades sempre expressas ao longo do processo editorial. Nosso agradecimento também aos tradutores dos artigos - Janete Silveira e Iury Paz Limeira. Em particular, colocamos os nossos agradecimentos a The York Management School - University of York (UK) pelo apoio na organização do número e cobertura dos custos de tradução dos artigos para a língua portuguesa.

Uma Boa Leitura a Todos! 